\title{
Mutation-induced loss of APP function causes GABAergic depletion in recessive familial Alzheimer's disease: analysis of Osaka mutation-knockin mice
}

Tomohiro Umeda ${ }^{1,2}$, Tetsuya Kimura ${ }^{3}$, Kayo Yoshida ${ }^{4}, K^{\prime}$ Keizo Takao ${ }^{5,8}$, Yuki Fujita ${ }^{1}$, Shogo Matsuyama ${ }^{6}$, Ayumi Sakai ${ }^{1}$, Minato Yamashita', Yuki Yamashita', Kiyouhisa Ohnishi', Mamiko Suzuki ${ }^{3}$, Hiroshi Takuma' ${ }^{1}$, Tsuyoshi Miyakawa ${ }^{5}$, Akihiko Takashima ${ }^{3}$, Takashi Morita ${ }^{4}$, Hiroshi Mori ${ }^{2,7}$ and Takami Tomiyama ${ }^{1,2^{*}}$ (D)

\begin{abstract}
The E693 $($ Osaka) mutation in APP is linked to familial Alzheimer's disease. While this mutation accelerates amyloid $\beta(A \beta)$ oligomerization, only patient homozygotes suffer from dementia, implying that this mutation is recessive and causes loss-of-function of amyloid precursor protein (APP). To investigate the recessive trait, we generated a new mouse model by knocking-in the Osaka mutation into endogenous mouse APP. The produced homozygous, heterozygous, and non-knockin littermates were compared for memory, neuropathology, and synaptic plasticity. Homozygotes showed memory impairment at 4 months, whereas heterozygotes did not, even at 8 months. Immunohistochemical and biochemical analyses revealed that only homozygotes displayed intraneuronal accumulation of A $\beta$ oligomers at 8 months, followed by abnormal tau phosphorylation, synapse loss, glial activation, and neuron loss. These pathologies were not observed at younger ages, suggesting that a certain mechanism other than $A \beta$ accumulation underlies the memory disturbance at 4 months. For the electrophysiology studies at 4 months, high-frequency stimulation evoked long-term potentiation in all mice in the presence of picrotoxin, but in the absence of picrotoxin, such potentiation was observed only in homozygotes, suggesting their GABAergic deficit. In support of this, the levels of GABA-related proteins and the number of dentate GABAergic interneurons were decreased in 4-month-old homozygotes. Since APP has been shown to play a role in dentate GABAergic synapse formation, the observed GABAergic depletion is likely associated with an impairment of the APP function presumably caused by the Osaka mutation. Oral administration of diazepam to homozygotes from 6 months improved memory at 8 months, and furthermore, prevented A $\beta$ oligomer accumulation, indicating that GABAergic deficiency is a cause of memory impairment and also a driving force of $A \beta$ accumulation. Our findings suggest that the Osaka mutation causes loss of APP function, leading to GABAergic depletion and memory disorder when wild-type APP is absent, providing a mechanism of the recessive heredity.
\end{abstract}

Keywords: Alzheimer's disease, Recessive mutation, Knockin mouse, Loss of function, GABA

\footnotetext{
* Correspondence: tomi@med.osaka-cu.ac.jp

'Department of Translational Neuroscience, Osaka City University Graduate

School of Medicine, 1-4-3 Asahimachi, Abeno-ku, Osaka 545-8585, Japan

${ }^{2}$ Core Research for Evolutional Science and Technology, Japan Science and

Technology Agency, Kawaguchi, Japan

Full list of author information is available at the end of the article
} 


\section{Introduction}

Cerebral accumulation of $A \beta$ oligomers is believed to be the initial step in the pathogenesis of Alzheimer's disease (AD) $[2,29] . A \beta$ is generated from amyloid precursor protein (APP) by the function of two distinct enzymes, $\beta$ - and $\gamma$-secretase [14]. $\gamma$-Secretase is a complex composed of at least four membrane proteins in which presenilin 1 or presenilin 2 constitutes the catalytic subunits. Genetic studies have found that mutations in $A P P$ (chromosome 21), PSEN1 (chromosome 14), and PSEN2 (chromosome 1) are linked to familial AD [3].

The inheritance of pathogenic mutations can be defined into two types, dominant and recessive, according to the impact of the mutant allele on the phenotype [22]. Dominant mutations cause disease even in heterozygotes by 1) gain-of-toxic-function of the gene product, 2) loss-of-function with dominant-negative effect, and 3) loss-of-function if $50 \%$ level of the normal gene product is not sufficient for normal gene function (haploinsufficiency). On the other hand, recessive mutations cause disease only in homozygotes primarily by loss-offunction: heterozygotes do not show pathogenic phenotypes, since the wild-type counterpart overcomes the deficiency of the mutant protein.

All pathogenic mutations in APP, PSEN1, and PSEN2 affect $A \beta$ production and/or aggregation and most of them are dominant [3]. Meanwhile, there are few recessive mutations reported. The E693 $\Delta$ (Osaka) mutation in APP, which corresponds to E22 $\Delta$ in $A \beta$, is the first recessive mutation identified in $\mathrm{AD}$ [25]. So far, two pedigrees with this mutation have been identified in Japan: one is in Osaka $[20,25]$ and the other is in the Inland Sea of Japan [11]. In both pedigrees, only homozygotes (2 members in Osaka and 3 members in the latter) suffer from dementia. However, it is unclear what kind of lossof-function is induced in patients. Studies with synthetic peptides revealed that this mutation accelerates $A \beta$ oligomerization, but never causes $A \beta$ fibrillization. When injected into the cerebral ventricle of normal rats, the mutant $A \beta$ peptides inhibited long-term potentiation (LTP) more potently than wild-type peptides [25]. Furthermore, in APP transgenic mice harboring this mutation (referred to as $\mathrm{APP}_{\mathrm{OSK}}$ mice), the produced $\mathrm{A} \beta$ formed abundant oligomers and accumulated within neurons to cause synaptic and cognitive impairment without forming amyloid plaques [26]. The enhanced $A \beta$ oligomer formation and the lack of senile plaques have also been suggested in homozygous human patients, which were surmised from Western blot of CSF samples and brain amyloid imaging [11, 20, 25]. Such phenotypes appear to represent gain-of-toxic-function, but nevertheless they are seen only in homozygotes. The second recessive mutation is the A673V mutation in APP, which corresponds to $\mathrm{A} 2 \mathrm{~V}$ in $\mathrm{A} \beta$ [5]. This mutation has been shown to increase $A \beta$ production and accelerate $A \beta$ fibrillization, but the mutant $A \beta$ do not aggregate when co-incubated with wild-type $A \beta$. Furthermore, what kind of loss-of-function is induced by this mutation is also unclear. Interestingly, A673T mutation at the same position in APP shows protective effects against AD by reducing $A \beta$ production and aggregation [7].

To investigate the genetic traits of recessive AD mutations more closely, we generated a new mouse model by knocking-in the Osaka mutation into endogenous mouse $A P P$. The produced knockin mice (referred to as OSK$\mathrm{KI}$ mice) displayed $\mathrm{A} \beta$ pathologies only in homozygotes. We noticed that their memory impairment preceded $A \beta$ accumulation and accompanied GABAergic depletion, which was presumably caused by the loss-of-function of APP. Thus, the present study provides new insights into the mechanism underlying the recessive heredity of the Osaka mutation.

\section{Materials and methods Generation of OSK-KI mice}

Mice harboring the Osaka mutation in their $A \beta$ sequence were generated by knocking-in this mutation into endogenous mouse $A P P$ by homologous recombination in embryonic stem cells. Mouse APP contains 18 exons, and $A \beta$ is coded in exons 16 and 17 (GenBank: U82624.1). The targeting vector (pTVneo/APP) was constructed according to the method of Thuy le et al. [24]. Three DNA fragments $\left(5^{\prime}\right.$, middle, and $\left.3^{\prime}\right)$ were produced by PCR from 129Sv mouse genomic DNA using the primer pairs indicated in Table 1 followed by restriction enzyme cleavage. The $5^{\prime} \mathrm{PCR}$ fragment $(4.4 \mathrm{~kb})$ contained APP intron 15, exon 16, intron 16, and the $5^{\prime}$ region of exon 17. The reverse PCR primer used for this fragment was designed to have a deletion of codon693 (GAA) in exon 17 (i.e. the Osaka mutation). The middle PCR fragment $(0.6 \mathrm{~kb})$ contained the 3 ' region of exon 17 and $5^{\prime}$ region of intron 17 . The two DNA fragments were ligated and used as the $5^{\prime}$ arm. The $3^{\prime}$ PCR fragment $(5.1 \mathrm{~kb})$ containing intron 17 was used as the 3' $\mathrm{arm}$. The neomycin-resistance gene, driven by the phosphoglycerate kinase 1 promoter, with flanking lox-P sequences was inserted into the arms. Mouse embryonic stem cells $\left(1 \times 10^{7}\right.$ cells $\left./ \mathrm{mL}\right)$ were transfected with the linearized targeting vector $(20 \mu \mathrm{g})$ by electroporation and cultured in selection medium containing $150 \mu \mathrm{g} / \mathrm{mL}$ geneticine (G418). Of 200 neomycin-resistant clones, only one $(0.5 \%)$ was a homologous recombinant, which was determined by Southern blot hybridization using the $5^{\prime}$ and $3^{\prime}$ probes (data not shown). The clone was aggregated with C57BL/6-DBA2 F1 mouse morulae, and the chimera embryos were transplanted into pseudopregnant mice. The produced chimeric male mice were mated with C57BL/6 J females to obtain germline transmitting 
Table 1 PCR primers used for targeting vector construction, probe preparation, and mouse genotyping

\begin{tabular}{|c|c|}
\hline Name & Sequence \\
\hline \multicolumn{2}{|l|}{ Targeting vector } \\
\hline TV-Am-5'-F (Notl) & 5'-ATAAGAATGCGGCCGCGTAGGAAGGCCCAGCTAGAAGGAAATGGG-3' \\
\hline TV-Am-5'-R (Narl) & 5'-CCGATGATGGCGCCTTTGTTCGAACCCACATC ( $\triangle T T C$ ) AGCAAAGAACACCTTCGAAAGGAAGCCG-3 \\
\hline TV-Am-M-F (Narl) & 5'-CGGCTTCCTTTCGAAGGTGTTCTTTGCT-3' \\
\hline TV-Am-M-R (Ascl) & 5'-TTGGCGCGCCAGTTAACTAGGCCTAATGTTCCTCCATGGTAACCACGC-3' \\
\hline TV-Am-3'-F (Pmel) & 5'-AGCTTTGTTTAAACAGGCTGTTGCCCTGAACTTCCACCTGAG-3' \\
\hline TV-Am-3' R (Aatll) & 5'-GGGGTTAGACGTCCCATTGGGTGTGACCCCACTTCAGAG-3' \\
\hline \multicolumn{2}{|l|}{ Southern probes } \\
\hline Am-5'-probe F & 5'-TCCCCCACCCCCTGTTATAAAAGG -3' \\
\hline Am-5' probe $\mathrm{R}$ & 5'-TGCTCTTTAAATCACCCCGGTTGC-3' \\
\hline Am-3'-probe F & 5'-TCCTCTCGTCTTCCAACGCGGCTT -3' \\
\hline Am-3'-probe R & 5'-CCGCCAGGCCAGAGCTCTACAGCA-3' \\
\hline \multicolumn{2}{|l|}{ Genotyping } \\
\hline $\mathrm{KI} / \mathrm{WT}$ forward & 5'-CCTAGGGACCCACCAACTCACGCT-3' \\
\hline WT reverse & 5'-GGTGGAAGTTCAGGGCAACAGCCT-3' \\
\hline $\mathrm{KI}$ reverse & 5'- TCTCCTGTCATCTCACCTTGCT-3' \\
\hline
\end{tabular}

KI mice that were backcrossed to the C57BL/6 J background for more than ten generations. Homozygous KI mice were generated by crossing heterozygotes. Genotyping was performed by PCR from mouse tail DNA using the primers indicated in Table 1. All animal experiments were approved by the committee of Osaka City University and were performed in accordance with the Guide for Animal Experimentation, Osaka City University. Every effort was made to minimize the number of animals used and their suffering.

\section{Antibodies}

Mouse monoclonal antibodies to $\mathrm{A} \beta$ oligomers (11A1; IBL, Fujioka, Japan), the presynaptic marker synaptophysin (SVP-38; Sigma, St. Louis, MO), the astrocyte marker glial fibrillary acidic protein (GFAP) (Cappel, Aurora, $\mathrm{OH}$ ), the mature neuron marker NeuN (Chemicon, Temecula, CA), and the GABAergic neuron marker parvalbumin (PARV-19; Sigma) were purchased. Rabbit polyclonal antibodies to the microglia marker Iba-1 (Wako, Osaka, Japan), GABA-synthetic enzyme glutamate decarboxylase (GAD) 65/67 (EMD Millipore, Temecula, CA), vesicular GABA transporter (VGAT) (Proteintech, Rosemont, IL), vesicular glutamate transporter (VGLUT) 1/2 (Abcam, Cambridge, MA) and actin (Sigma) were also purchased. Mouse monoclonal antibody to pSer396/ Ser404-tau (PHF-1) was a kind gift from Dr. Peter Davies
(Department of Pathology, Albert Einstein College of Medicine, Bronx, NY), and rabbit polyclonal antibodies to A 342 (Ter42), A $\beta$ N-terminus ( $\beta 001)$, and APP Cterminus (C40) were prepared in our laboratory.

\section{Behavioral analysis}

Spatial reference memory of male mice was assessed in Osaka City University at 4, 6, and 8 months using the Morris water maze, as described previously [28]. In addition, comprehensive behavioral test battery was performed in the National Institute for Physiological Sciences on 8-month-old male mice to study their sensorimotor functions, locomotor activity, social behavior, anxiety-like behavior, depression-like behavior, and learning/memory, as described previously [10].

\section{Immunohistochemical analysis}

Brain sections were prepared as described previously [26]. A $\beta$ accumulation (Ter42, $\beta 001$ and 11A1), abnormal tau phosphorylation (PHF-1), synapse loss (synaptophysin), and glial activation (GFAP and Iba-1), were examined as described previously [26], where only for $\mathrm{A} \beta$ staining, sections were pretreated by boiling in $0.01 \mathrm{~N} \mathrm{HCl}(\mathrm{pH} 2)$ for $10 \mathrm{~min}$ to expose epitopes. Neuronal loss was assessed with anti-NeuN antibody with (entorhinal) or without (hippocampus) boiling sections in $10 \mathrm{mM}$ citrate buffer ( $\mathrm{pH}$ ) for $30 \mathrm{~min}$. GABAergic 
interneurons were stained with anti-parvalbumin antibody after sections were boiled in $10 \mathrm{mM}$ citrate buffer (pH 6) for $30 \mathrm{~min}$.

\section{Biochemical analysis}

To determine the expression levels of APP, brain tissues were homogenized in 5 volumes of $50 \mathrm{mM}$ Tris- $\mathrm{HCl}$ (pH 7.6), $150 \mathrm{mM} \mathrm{NaCl}$ (Tris-buffered saline, TBS) containing 1\% Triton X-100 and protease inhibitor cocktail (P8340; Sigma). After agitation at $4{ }^{\circ} \mathrm{C}$ for $1 \mathrm{~h}$, the homogenates were centrifuged at $1000 \mathrm{x} \mathrm{g}$ for $15 \mathrm{~min}$ at $4{ }^{\circ} \mathrm{C}$ to remove insoluble materials. The supernatants were subjected to Western blot with antibodies to APP C-terminus (C40) and actin. In different experiments, hippocampal tissues were dissected from mouse brains and homogenized in 4 volumes of TBS containing P8340. The levels of synaptophysin, GAD65/67, VGAT, VGLUT1/ 2 , and actin were examined by Western blot with corresponding antibodies. Signals were visualized and quantified using an ImageQuant LAS 500 (GE Healthcare BioSciences, Uppsala, Sweden). The remaining brain tissues, not including the cerebellum, were also homogenized in 4 volumes of TBS containing P8340 and separated into TBS-soluble and SDS-soluble fractions by 2-step ultracentrifugation, the latter of which were dialyzed against TBS, essentially as described previously [28]. The levels of A $\beta 42$ in each fraction were measured using the Sensolyte anti-mouse/rat $\beta$-amyloid (1-42) quantitative ELISA kit Colorimetric (Anaspec, Fremont, CA). A $\beta$ oligomers and phosphorylated tau in the homogenates were measured by direct ELISA with $11 \mathrm{~A} 1$ antibody and by using the Human Tau [pS396] ELISA kit (Invitrogen, Camarillo, CA), respectively, as described previously [28].

\section{Electrophysiological analysis}

Synaptic plasticity was examined by electrophysiology using hippocampal slices, essentially as described previously [32]. Transverse hippocampal slices (350 $\mu \mathrm{m}$ thick) were prepared in ice-cold artificial cerebrospinal fluid (aCSF; $\mathrm{NaCl} 124 \mathrm{mM}, \mathrm{KCl} 3 \mathrm{mM}, \mathrm{NaHCO}_{3} 26 \mathrm{mM}$, $\mathrm{NaH}_{2} \mathrm{PO}_{4} 1.25 \mathrm{mM}, \mathrm{CaCl}_{2} 2 \mathrm{mM}, \mathrm{MgSO}_{4} 1 \mathrm{mM}$, and D-glucose $10 \mathrm{mM}$ ) containing $1 \mathrm{mM}$ kynurenic acid. Slices were allowed to recover in aCSF at room temperature for $1-2 \mathrm{~h}$ and then transferred to the recording chamber, in which they were perfused at a rate of $2 \mathrm{ml} / \mathrm{min}$ with aCSF at $32{ }^{\circ} \mathrm{C}$. Electrical stimulation was applied onto the molecular layer of dentate gyrus using a bipolar tungsten electrode, and field excitatory postsynaptic potential (fEPSP) was recorded using a glass electrode in the same region at $200-\mu \mathrm{m}$ distance from the stimulating electrode. Baseline stimulation was $15-$ to $20-\mu \mathrm{A}$ constant current pulse, which induces fEPSP at a level $50 \%$ the maximum amplitude, $100-\mu$ sec pulse duration, and 30-s pulse interval. After baseline recording for $15 \mathrm{~min}$, high-frequency stimulation (HFS; 3 trains of $100 \mathrm{~Hz}, 100$ pulses, 120-s train interval) with an intensity 2-fold higher than that of baseline stimulation was delivered. The produced fEPSP was recorded for $60 \mathrm{~min}$ in the presence or absence of a $\mathrm{GABA}_{\mathrm{A}}$ receptor antagonist picrotoxin (Sigma) at $40 \mu \mathrm{M}$. fEPSP slopes were compared at $60 \mathrm{~min}$.

\section{Diazepam treatment to OSK-KI mice}

Diazepam (Sigma), a positive allosteric modulator of $\mathrm{GABA}_{\mathrm{A}}$ receptor, was dissolved to $10 \mu \mathrm{g} / \mathrm{ml}$ in $0.5 \%$ low-viscosity carboxymethylcellulose (CMC; Sigma). Diazepam is usually prescribed to adult humans at 2 to $10 \mathrm{mg}$ orally 2 to 4 times a day for anxiety and seizures (https://www.drugs.com/dosage/ diazepam.html). Thus, its minimum daily dose for humans is $4 \mathrm{mg}$. Assuming that mean body weights of adult humans and mice are $60 \mathrm{~kg}$ and $30 \mathrm{~g}$, respectively, the minimum daily dose for mice corresponds to $2 \mu \mathrm{g}$. Thus, $200 \mu \mathrm{l}$ of diazepam (i.e. $2 \mu \mathrm{g}$ ) or CMC solution was orally administered using feeding needles to 6-month-old male homozygotes ( $n=9-10$ per group) 5 days a week (Monday through Friday) for 2 months. Age-matched male non-KI littermates $(n=10)$ administered CMC solution were used as controls. Spatial reference memory was examined at 8 months using the Morris water maze as described above. Daily oral administration of diazepam was continued during the behavioral test. After the behavioral tests, brain sections were prepared and $A \beta$ oligomer accumulation (11A1), synapse loss (synaptophysin), and GABAergic neurons (parvalbumin) were examined by immunohistochemistry as described above.

\section{Transfection and western blot of mouse $A \beta$ oligomers}

Human APP695 constructs with the Swedish (K670 N/ M671 L, SW) and Osaka mutations were prepared as described previously [13], from which mouse APP695 constructs were produced by site-directed mutagenesis. HEK293 cells were transfected with human or mouse $\mathrm{APP}_{\mathrm{SW}}$ and $\mathrm{APP}_{\mathrm{SW} / \mathrm{OSK}}$ constructs, as described previously [13]. The Swedish mutation was introduced just to increase total $\mathrm{A} \beta$ production. Three days after transfection, the cells from 5 culture dishes $(10 \mathrm{~cm}$ diameter $)$ were combined into 1 tube and homogenized by sonication in $1 \mathrm{~mL}$ of $1 \%$ Triton X-100/TBS containing P8340. After agitation at $4{ }^{\circ} \mathrm{C}$ for $1 \mathrm{~h}$, the cell homogenates were centrifuged at $1000 \mathrm{x}$ g for $15 \mathrm{~min}$ at $4{ }^{\circ} \mathrm{C}$ to remove cell debris. Aliquots of the supernatants were subjected to Western blot to measure APP expression $(C 40)$ and actin. $A \beta$ in the remaining supernatants were immunoprecipitated using anti-A $\beta$ antibody $\beta 001$ and subjected to Western blot with the same antibody, 


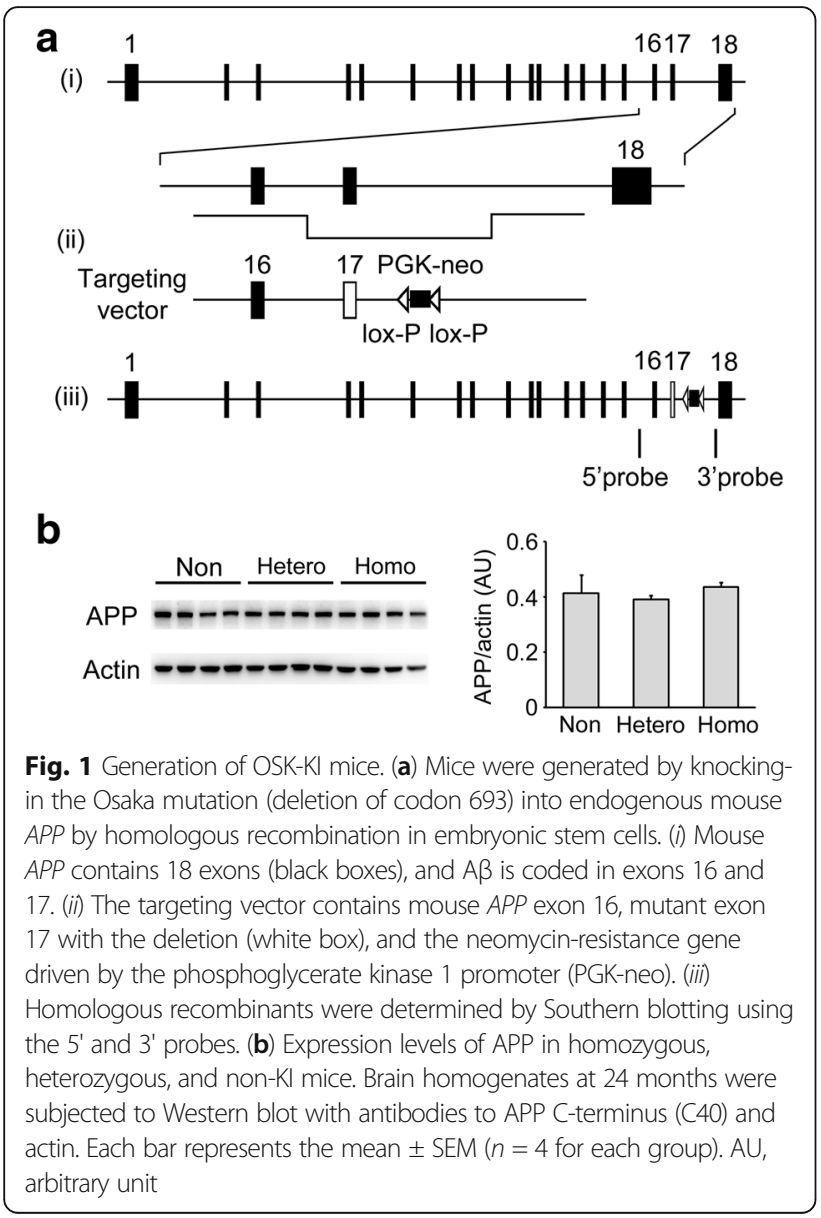

essentially as described previously [13]. Signals were visualized and quantified using an ImageQuant LAS 500.

\section{Statistical analysis}

Comparisons of means between more than two groups were performed using the Bonferroni/Dunn test in immunohistochemical and biochemical analyses, and the comparison of fEPSP slopes at $60 \mathrm{~min}$ in electrophysiology was done using the Tukey-Kramer test. Data in behavioral tests were analyzed using ANOVA or repeated measures ANOVA followed by the TukeyKramer test. Differences with a $p$ value of less than 0.05 were considered significant.

\section{Results}

\section{Generation of OSK-KI mice}

OSK-KI mice were generated by homologous recombination with a targeting vector containing mouse $A P P$ fragment around exon 17 in which codon 693 was deleted (Fig. 1a). The obtained heterozygous male and female KI mice were crossed with each other to produce homozygotes. The ratio of homozygous, heterozygous, and non-KI offspring was approximately 1:2:1. These mice all appeared normal. Homozygotes produced only mutant mouse $A \beta$, while heterozygotes produced both wild-type and mutant mouse $A \beta$. There were no differences in the levels of endogenous APP among the homozygote, heterozygote, and non-KI groups (Fig. 1b).

\section{Memory impairment in OSK-KI mice}

We initially tested spatial reference memory of OSK-KI mice at 4, 6, and 8 months using the Morris water maze. Compared with non-KI littermates, homozygotes showed impaired memory early at 4 months, whereas heterozygotes maintained memory at similar levels even at 8 months (Fig. 2). This result is in agreement with our previous finding in humans that the Osaka mutation causes dementia in a recessive hereditary manner [25].

Comprehensive behavioral study was performed on 8-month-old OSK-KI mice. Almost no significant differences were observed among homozygotes, heterozygotes, and non-KI mice except for few parameters including body weight, motor coordination, and locomotor activity in dark (Table 2).

\section{$A \beta$-related neuropathology in OSK-KI mice}

Then we examined the neuropathology of OSK-KI mice at various ages. $A \beta$ accumulation was visualized by
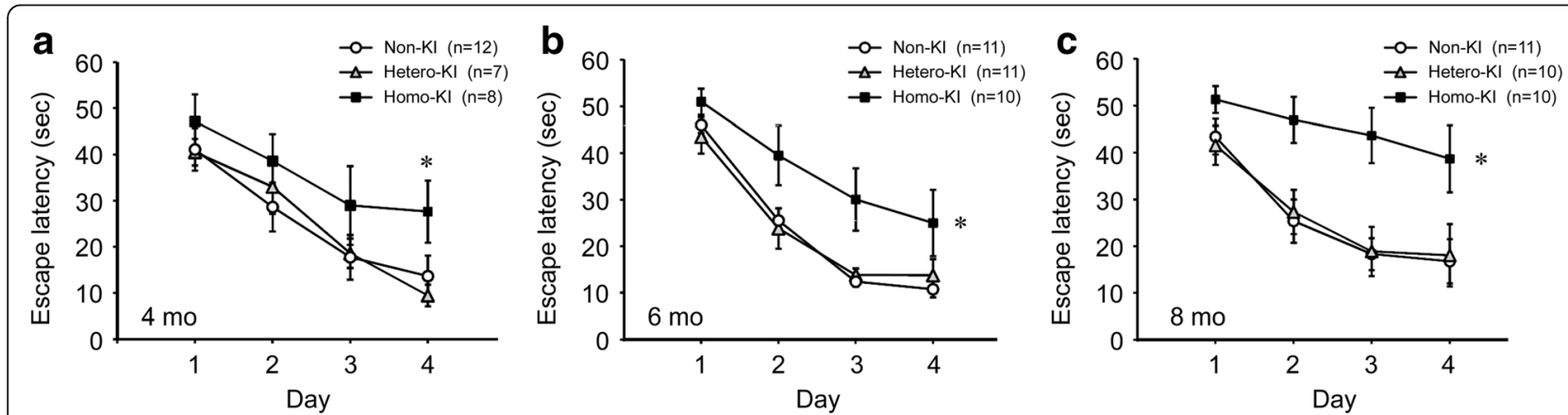

Fig. 2 Memory impairment in OSK-KI mice. Spatial reference memory of mice was examined at 4 (a), 6 (b), and 8 months (c) using the Morris water maze. Each point represents the mean latency of five trials per day \pm SEM. (a) ${ }^{*} p<0.05$ versus hetero-KI when means of day 4 were separately compared using the Tukey-Kramer test. (b) ${ }^{*} p<0.05$ versus non-Kl and $<0.05$ versus hetero-Kl. (c) ${ }^{*} p<0.05$ versus non-Kl and $<0.05$ versus hetero-Kl 
Table 2 Phenotypes of OSK-KI mice in comprehensive behavioral test battery

\begin{tabular}{|c|c|c|c|}
\hline \multirow[t]{2}{*}{ Tests } & \multirow{2}{*}{$\begin{array}{l}\text { Hetero-KI } \\
\text { (vs. Non-KI) }\end{array}$} & \multicolumn{2}{|l|}{ Homo-KI } \\
\hline & & (vs. Non-KI) & (vs. Hetero-KI) \\
\hline \multicolumn{4}{|l|}{ Somatic parameters } \\
\hline Body weight & - & - & $\downarrow^{1}$ \\
\hline Body temperature & - & - & - \\
\hline Grip strength & - & - & - \\
\hline Wire-hanging time & - & - & - \\
\hline \multicolumn{4}{|l|}{ Light/dark transition test } \\
\hline Anxiety & - & - & $\downarrow^{2}$ \\
\hline \multicolumn{4}{|l|}{ Open field } \\
\hline Exploratory locomotion & - & - & - \\
\hline \multicolumn{4}{|l|}{ Elevated plus maze } \\
\hline Anxiety & - & - & - \\
\hline \multicolumn{4}{|l|}{ Rotarod } \\
\hline Motor coordination & $\downarrow^{3}$ & $\downarrow^{3}$ & - \\
\hline \multicolumn{4}{|l|}{ Hot plate } \\
\hline Pain sensitivity & - & - & - \\
\hline $\begin{array}{l}\text { Social interaction test } \\
\text { (novel environment) }\end{array}$ & - & - & - \\
\hline $\begin{array}{l}\text { Social interaction test } \\
\text { (Crawley's version) }\end{array}$ & - & - & - \\
\hline \multicolumn{4}{|l|}{ Startle Response/Prepulse inhibition } \\
\hline Sensorimotor gating & $\downarrow^{4}$ & - & $\uparrow^{4}$ \\
\hline \multicolumn{4}{|l|}{ Porsolt forced swim } \\
\hline Immobility time (behavioral despair) & - & - & - \\
\hline \multicolumn{4}{|l|}{ Barns maze } \\
\hline Spatial memory & - & $\uparrow^{5}$ & - \\
\hline \multicolumn{4}{|l|}{ Eight-arm radial maze } \\
\hline Working memory & - & $\uparrow^{6}$ & - \\
\hline \multicolumn{4}{|l|}{ T-maze forced alternation } \\
\hline Working memory & - & - & - \\
\hline \multicolumn{4}{|l|}{ Gait analysis } \\
\hline Gait ataxia & - & - & - \\
\hline \multicolumn{4}{|l|}{ Fear conditioning } \\
\hline Contextual fear memory & - & - & - \\
\hline \multicolumn{4}{|l|}{ Tail suspension } \\
\hline Immobility time (behavioral despair) & - & - & - \\
\hline $\begin{array}{l}\text { Social interaction test } \\
\text { ( } 24-\mathrm{h} \text { homecage monitoring) }\end{array}$ & - & $\downarrow^{7}$ & - \\
\hline
\end{tabular}

(24-h homecage monitori

Comprehensive behavioral test battery was performed on 8-month-old male mice as described previously [10]. The numbers of mice used in each test were $n=15-17$ for non-KI, $n=16-20$ for hetero-Kl, and $n=12-16$ for homo-KI except for the social interaction tests (novel environment and 24-h homecage monitoring) in which $n=7-9$ for non-KI, $n=8-10$ for hetero-Kl, and $n=6-8$ for homo-KI. - , no significant difference was detected. $\downarrow^{1}$, body weight of homo-KI was slightly but significantly $(p<0.05)$ lower than that of hetero-KI. $\downarrow^{2}$, distance traveled in dark of homo-KI was slightly but significantly $(p<0.05)$ lower than that of hetero-KI. $\downarrow^{3}$, latency to fall of hetero-KI was significantly $(p<0.05)$ lower than that of non-KI; latency to fall of homo-KI was also lower than that of non-KI, but the difference was not significant. $\downarrow^{4}$ and $\uparrow^{4}$, prepulse inhibition of hetero-KI was lower than those of non-KI and homo-KI, but the differences were not significant. $\uparrow^{5}$, error to 1 st of homo-KI was slightly but significantly $(p<0.05)$ lower (i.e. improved) than that of non-KI. $\uparrow^{6}$, different arm choices in first 8 entries of homo-KI was slightly but significantly $(p<0.05)$ higher (i.e. improved) than that of non-KI. $\downarrow^{7}$, activity level in dark of homo-KI was significantly $(p<0.05)$ lower than that of non-KI 
immunohistochemistry with anti-A $\beta 42$ (Ter42), anti-A $\beta$ $\mathrm{N}$-terminus ( $\beta 001$ ), and $\mathrm{A} \beta$ oligomer-specific antibodies (11A1). Homozygotes exhibited intraneuronal accumulation of $A \beta$ in the cerebral cortex, hippocampus, dentate gyrus, and entorhinal cortex at 8 months (Fig. 3a, b).
These $A \beta$ were also positive to $11 \mathrm{~A} 1$ antibody (Fig. $3 \mathrm{c}$ ), indicating that they formed oligomers. In contrast, heterozygotes showed $A \beta$ accumulation only slightly at 24 months, which was similar to that of age-matched non-KI littermates. None of the three groups displayed
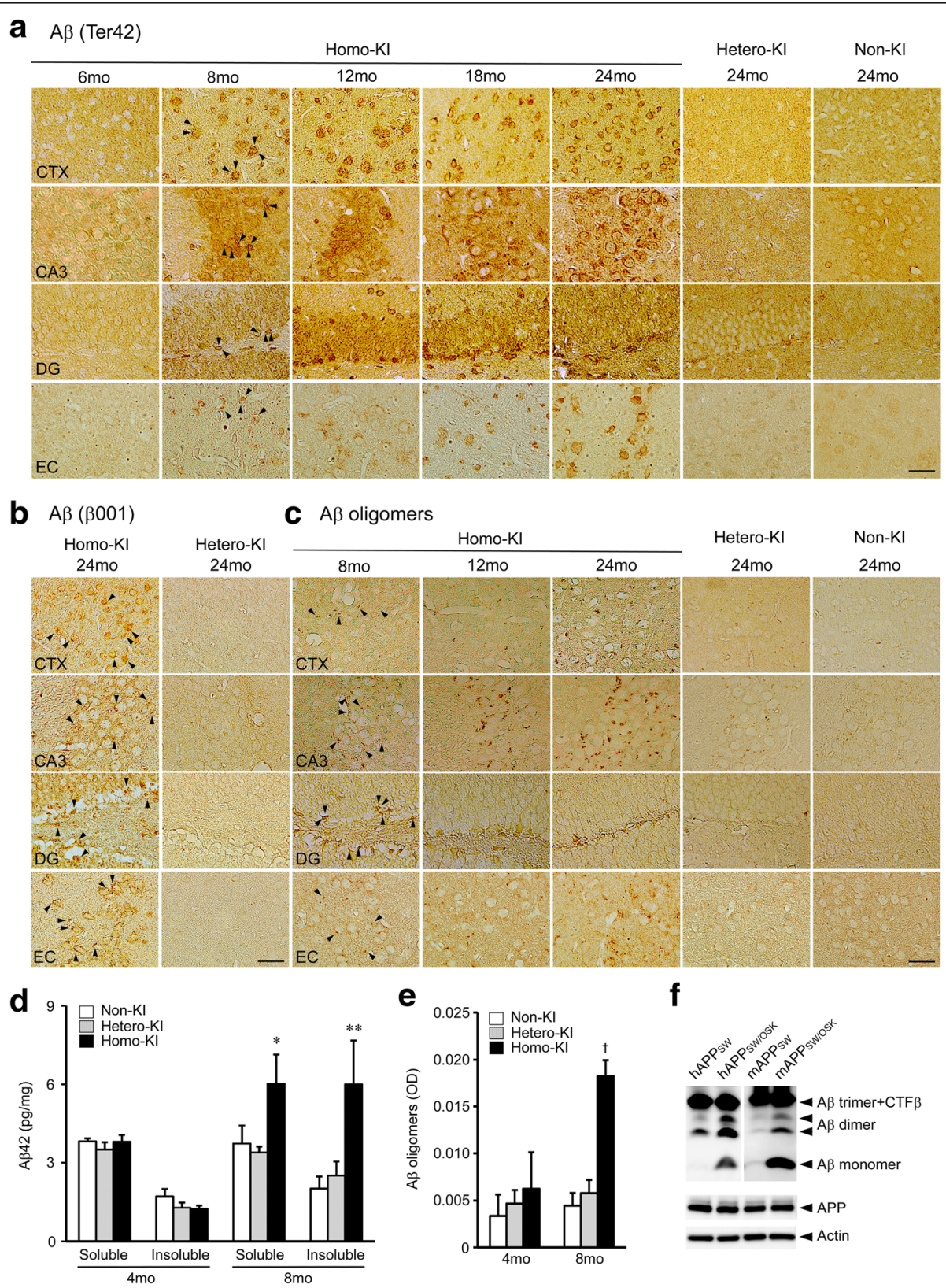

Fig. 3 A accumulation in OSK-KI mice. Brain sections were stained with anti-A 342 Ter42 (a), anti-A $\beta$ N-terminus $\beta 001$ (b) and A oligomer-specific $11 \mathrm{~A} 1$ antibodies (c). Photographs were taken from the posterior parietal association area (PPtA) of the cerebral cortex (CTX), hippocampal CA3 region (CA3), dentate gyrus (DG), and entorhinal cortex (EC). Arrowheads indicate $A \beta$ accumulated within neurons. Scale bar $=30 \mu \mathrm{m}$. (d) Brain homogenates at 4 and 8 months were separated into TBS-soluble and insoluble (SDS-soluble) fractions and subjected to Aß42 sandwich ELISA. Each bar represents the mean $\pm \operatorname{SEM}\left(n=4\right.$ for each group). ${ }^{*} p=0.0391$ versus hetero-KI, ${ }^{* *} p=0.0255$ versus non-KI and $=0.0441$ versus hetero-Kl. (e) For A $\mathrm{B}$ oligomers, brain homogenates were subjected to direct ELISA with 11A1 antibody. Each bar represents the mean \pm SEM ( $n=4$ for each group). $t p=0.0001$ versus non-Kl and $=0.0002$ versus hetero-KI. (f) HEK293 cells were transfected with human ( $h$ ) or mouse $(m)$ APP $_{\text {sw }}$ and APP sw/osk Constructs. Three days after transfection, the cells were homogenized and subjected to Western blot to measure APP expression (C40) and actin. Intracellular AB were immunoprecipitated using anti-A $\beta$ antibody $\beta 001$ and subjected to Western blot with the same antibody 
extracellular amyloid deposits. An accumulation of $A \beta 42$ and $A \beta$ oligomers in 8-month-old homozygotes was confirmed by ELISA (Fig. 3d, e). The enhanced oligomerization of Osaka-mutant mouse $A \beta$ was also shown in transfected cells. Immunoprecipitation/Western blot analysis revealed that Osaka-mutant mouse $A \beta$ formed oligomers (primarily dimers) more abundantly than wild-type mouse $A \beta$ and accumulated within cells, similarly to Osaka-mutant human $A \beta$ [13] (Fig. 3f). Thus, the Osaka mutation was shown to have $A \beta$ gainof-toxic-function by which $A \beta$ oligomerization is accelerated, not only in the human but also mouse $A \beta$ sequence. However, this phenotype was seen only in homozygotes, suggesting that the gain-of-toxic-function is insufficient or regulated by some factor.

Abnormal tau phosphorylation was examined by immunohistochemistry with PHF-1 antibody. Again, only homozygotes showed positive staining in hippocampal mossy fibers at 8 months (Fig. 4a). An increase of phosphorylated tau in 8-month-old homozygotes was confirmed by ELISA (Fig. 4b). Synapse loss was evaluated in the hippocampus by immunohistochemistry with antisynaptophysin antibody. Compared with non-KI littermates, homozygotes showed a marked decrease in synaptophysin level at 8 months, while heterozygotes exhibited a significant decrease only at 24 months (Fig. 4c). A decrease of synaptophysin in 8-month-old homozygotes was confirmed by Western blot (Fig. 4d). Glial activation was assessed by immunohistochemistry with antibodies to markers of microglia (Iba-1) and astrocyte (GFAP). We observed increased levels in Iba-1positive and GFAP-positive cells in the hippocampus at 12 months in homozygotes (Fig. 4e). In contrast, no apparent increase was detected in either heterozygotes or non-KI littermates even at 24 months. Finally, neuronal loss was estimated in the hippocampus and entorhinal cortex by immunohistochemistry with an antibody to a mature neuron marker, NeuN. Compared with non-KI littermates, homozygotes but not heterozygotes showed a significant decrease in NeuN-positive cells in both regions at 24 months (Fig. 4f).

These results indicate that the Osaka mutation causes $A \beta$-related neuropathology in a recessive hereditary manner. However, these phenotypes were recognized only from 8 months, suggesting that a certain unidentified mechanism other than $A \beta$ accumulation underlies the memory disturbance observed in 4-month-old homozygotes.

\section{Aberrant synaptic activity in OSK-KI mice}

We next studied synaptic plasticity in OSK-KI mice at 4 and 8 months by electrophysiology using hippocampal slices. HFS was delivered to the dentate gyrus, and fEPSP was recorded in the same region in the presence and absence of a $\mathrm{GABA}_{\mathrm{A}}$ receptor antagonist, picrotoxin, as LTP induction has been shown to be sensitive to GABAergic input [32]. In the presence of picrotoxin, LTP was evoked to similar levels in homozygotes, heterozygotes and non-KI mice at 4 months (Fig. 5a). However, at 8 months, the level of LTP in homozygotes was significantly lower than those of heterozygotes and non-KI mice (Fig. 5b). The LTP inhibition observed in homozygotes was presumably caused by $\mathrm{A} \beta$ oligomers, which have been shown to impair glutamatergic signaling [27], a phenomenon similar to that in $\mathrm{APP}_{\mathrm{OSK}}$ mice [26]. In the absence of picrotoxin, on the other hand, only homozygotes but not heterozygotes nor non-KI mice displayed LTP at 4 and 8 months (Fig. 5c, d). These observations indicate that in heterozygotes and non-KI mice, GABAergic transmission was normal and suppressed LTP induction under the conditions we used. In contrast, the same HFS induced LTP in homozygotes, suggesting that their GABAergic transmission was disrupted. This problem occurred early (4 months) and at the same time as memory impairment. The level of LTP in homozygotes in the absence of picrotoxin was also attenuated at 8 months, probably due to their glutamatergic impairment.

\section{GABAergic neuron loss in OSK-KI mice}

APP has been reported to be highly expressed in GABAergic interneurons in the dentate gyrus and plays an important role in GABAergic synapse formation [30]. This information led us to speculate that the Osaka mutation may impair the APP function necessary for GABAergic neurons and thereby cause the deficiency of GABAergic transmission in the dentate gyrus. Thus, we measured the number of GABAergic neurons in the dentate gyrus at 4 months. Brain sections were stained with antibody to parvalbumin, a marker of GABAergic neurons. Compared with non-KI littermates, homozygotes showed a significant decrease in parvalbuminpositive cells in the dentate gyrus, but heterozygotes did not (Fig. 6a). In the entorhinal cortex, on the other hand, parvalbumin-positive cells showed a tendency to decrease in homozygotes, but the differences were not significant (Fig. 6a). The decrease of GABAergic neurons in 4month-old homozygotes was confirmed by Western blot with antibodies to the GABA-synthetic enzyme GAD65/67 and the GABA transporter VGAT (Fig. 6b). In contrast, glutamatergic neurons were not affected in 4-month-old homozygotes, as shown in Western blot with an antibody to the glutamate transporter VGLUT1/2 (Fig. 6b).

\section{Effects of diazepam treatment on memory and $A \beta$ pathology in OSK-KI mice}

In homozygotes, GABAergic depletion and memory impairment occurred at 4 months, and $A \beta$ accumulation 


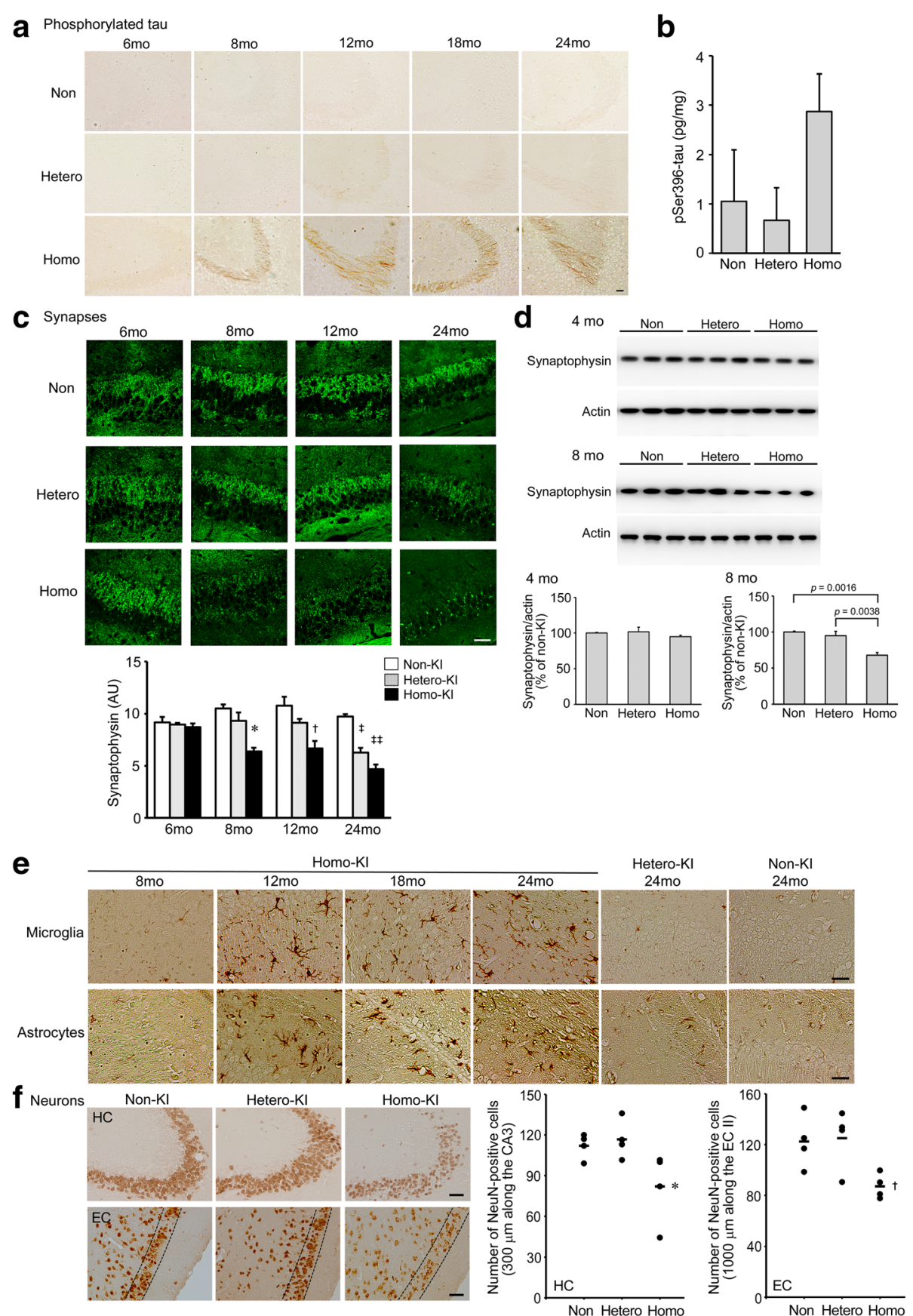

Fig. 4 (See legend on next page.) 


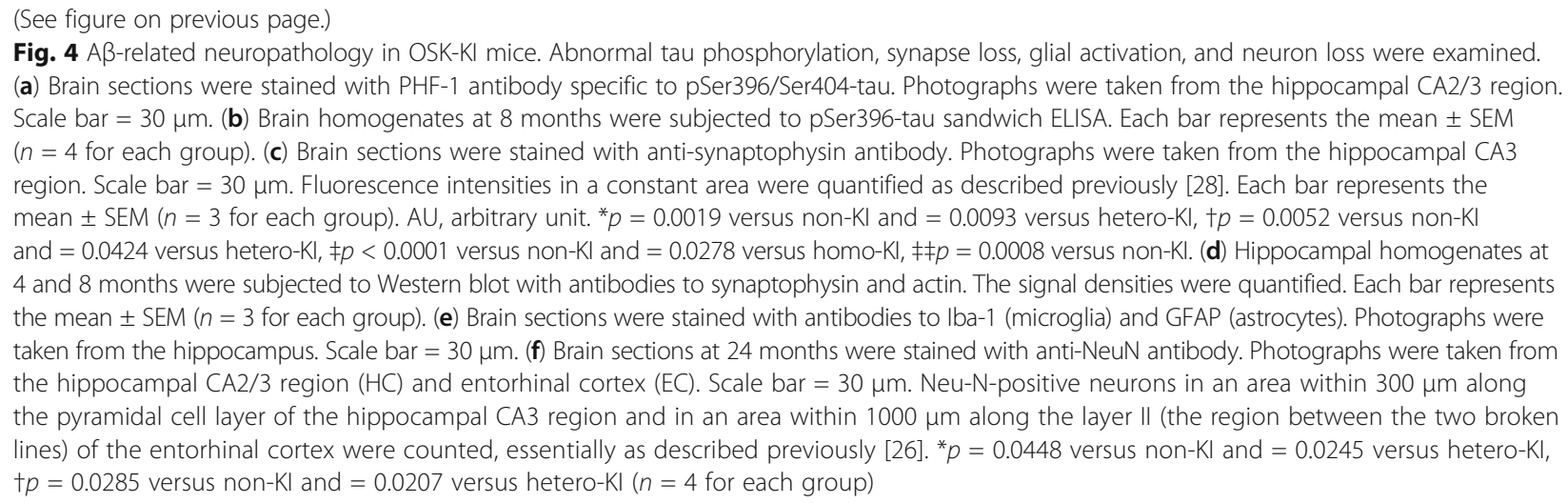

was detected at 8 months. Is there any causal relationship between these events? Since $A \beta$ production has been shown to depend on neuronal activity $[8,17]$ and since GABA is an inhibitory neurotransmitter, we speculate that GABAergic depletion may cause aberrant neuronal activation and thereby accelerate $A \beta$ production and accumulation. If so, compensative treatment with GABA agonists would prevent $A \beta$ accumulation in homozygotes. To test this hypothesis, we orally administered diazepam, a member of benzodiazepines and a positive allosteric modulator of $\mathrm{GABA}_{\mathrm{A}}$ receptor, to homozygotes from 6 months and examined their memory and $A \beta$ pathology at 8 months. Diazepam treatment improved memory (Fig. 7a) and prevented $A \beta$ oligomer accumulation (Fig. 7b) and synapse loss (Fig. 7c), but did not affect parvalbumin-positive GABAergic neurons in the dentate gyrus (Fig. 7d) in homozygotes. These results indicate that $A \beta$ accumulation in OSK-KI mice depends on early GABAergic depletion.

\section{Discussion}

In the present study, we generated a new mouse model of $\mathrm{AD}$ by knocking-in the Osaka mutation into endogenous mouse APP. The produced OSK-KI mice successfully displayed memory impairment, $A \beta$ oligomer accumulation, and subsequent $A \beta$-related pathology. Since the exact neuropathology in human patients with the Osaka mutation is not known, we cannot validate the phenotypes of OSK-KI mice at the moment. Nevertheless, it is important that the above phenotypes were seen only in homozygotes, reflecting the recessive heredity of the Osaka mutation that was originally observed in humans [11, 20, 25]. In general, recessive mutations cause disease primarily by loss-of-function of the gene product [22]. The fact that the Osaka mutation is recessive implies that this mutation induces a loss-of-function of APP. Then, what kind of loss-offunction is induced by the Osaka mutation? A hint was found in the paper of Wang et al. [30], where they demonstrated using APP knockout mice that APP is highly expressed in GABAergic interneurons in the dentate gyrus and plays an important role in GABAergic synapse formation. This information led us to speculate that the Osaka mutation impairs the APP function necessary for the formation and maintenance of GABAergic synapses. If this were the case, homozygous OSK-KI mice would show deficient GABAergic transmission in the dentate gyrus, which presumably leads to abnormal synaptic activation and resultant memory impairment. Our data appear to support this theory: 4-month-old homozygotes displayed decreased levels of dentate GABAergic neurons, abnormal LTP induction, and impaired memory. This GABAergic depletion was not likely caused by $A \beta$ oligomers, because $A \beta$ accumulation was first detected at 8 months and because only GABAergic, but not glutamatergic, neurons were affected at 4 months. Furthermore, only dentate, but not entorhinal, GABAergic neurons were significantly decreased, despite that the both regions accumulated $\mathrm{A} \beta$ oligomers. We also showed that the memory impairment in homozygotes could be rescued by oral administration of diazepam, an allosteric modulator of $\mathrm{GABA}_{\mathrm{A}}$ receptor to promote GABA binding and thereby enhance GABAergic inhibitory input. This finding further supports our theory that GABAergic depletion is a cause of memory disturbance.

Homozygous OSK-KI mice, which express only mutant mouse APP, exhibited a marked accumulation of $\mathrm{A} \beta$ oligomers at 8 months similarly to $\mathrm{APP}_{\mathrm{OSK}}$ mice that overexpress mutant human APP. This finding indicates that the toxic effect of the Osaka mutation on $A \beta$ oligomerization is strong enough to be displayed not only in the human but also in the mouse $A \beta$ sequence. We confirmed this conclusion in transfected cells, in which Osaka-mutant mouse $A \beta$ formed oligomers more abundantly than wild-type, similarly to 

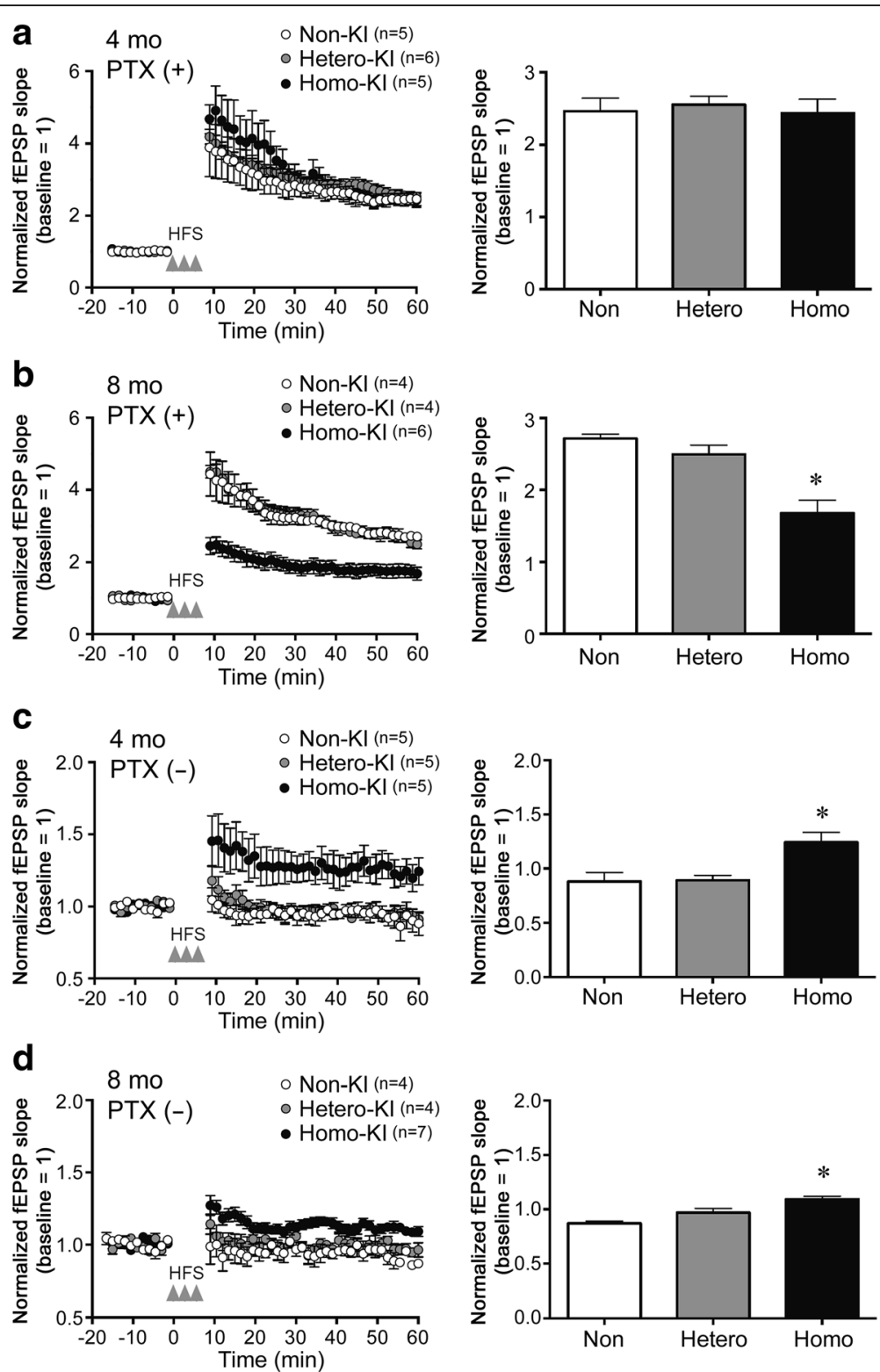

Fig. 5 Aberrant synaptic activity in OSK-KI mice. Synaptic plasticity was examined by electrophysiology using hippocampal slices at 4 (a, c) and 8 months (b, d). HFS (100 Hz, 100 pulses) was delivered to the dentate gyrus and fEPSP was recorded for 60 min in the same region in the presence $(\mathbf{a}, \mathbf{b})$ and absence $(\mathbf{c}, \mathbf{d})$ of $40 \mu \mathrm{M}$ picrotoxin. Right panels, the levels of fEPSP slope at 60 min were compared. Each bar represents the mean \pm SEM. ${ }^{*} p<0.05$ versus non-KI and $<0.05$ versus hetero-KI

Osaka-mutant human $A \beta$. Nevertheless, the phenotype was detected only in homozygotes. While many other APP mutations that affect $A \beta$ aggregation are dominant, why does the Osaka mutation show recessive inheritance? We noticed that $A \beta$ oligomer accumulation was detected only after the onset of GABAergic depletion. This order of appearance might indicate some causal relationship between these two events. $A \beta$ production has been shown to rely on neuronal activity $[8,17]$, and GABA is an inhibitory neurotransmitter. Thus, it is likely that $\mathrm{A} \beta$ production is negatively regulated by GABAergic transmission. If so, GABAergic deficiency would result in an accelerated $A \beta$ production and accumulation via abnormal synaptic activation. This story is plausible because diazepam treatment to homozygotes from 6 months prevented $A \beta$ oligomer accumulation at 8 months. This explains why the Osaka mutation shows recessive inheritance in spite of its gain-of-toxic-function: Accumuation of $A \beta$ oligomers would not occur until 
a
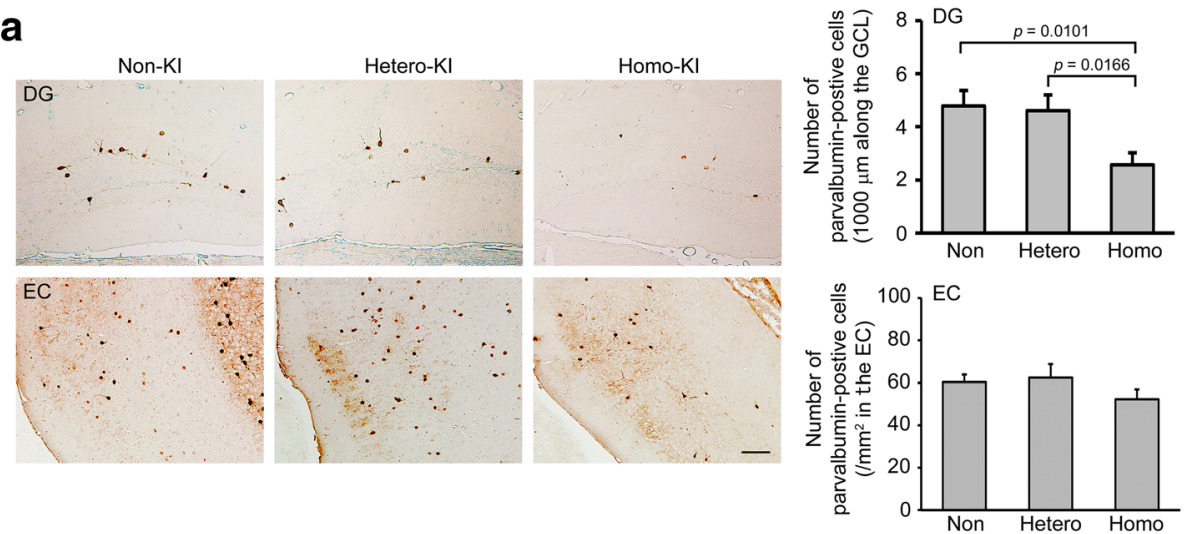

b
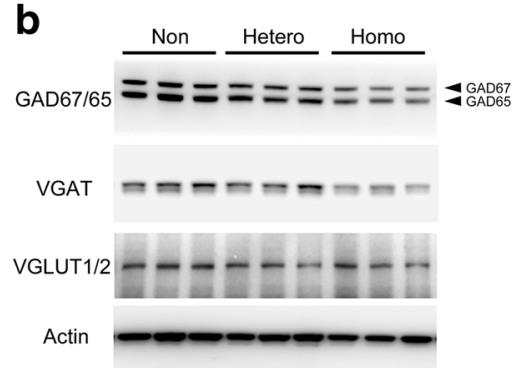
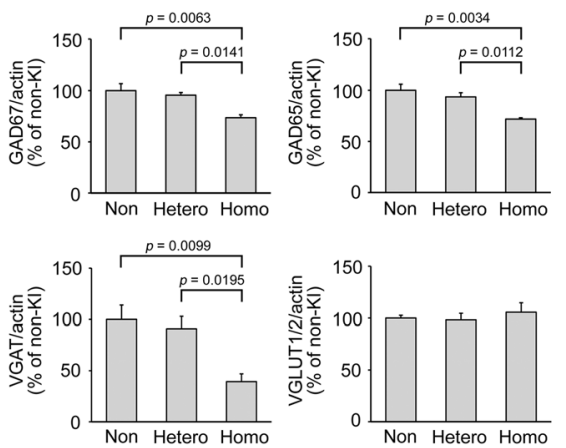

Fig. 6 GABAergic neuron loss in OSK-KI mice. (a) Brain sections at 4 months were stained with anti-parvalbumin antibody. Photographs were taken from the dentate gyrus (DG) and entorhinal cortex (EC). Scale bar $=30 \mu \mathrm{m}$. Parvalbumin-positive GABAergic neurons in the granular cell layer (GCL) of the dentate gyrus within $1000 \mu \mathrm{m}$ and in an area $(700 \times 600 \mu \mathrm{m})$ of the entorhinal cortex were counted. Each bar represents the mean \pm SEM ( $n=7$ for each group). (b) Hippocampal homogenates at 4 months were subjected to Western blot with antibodies to GAD67/65 (GABA-synthetic enzyme), VGAT (GABA transporter), VGLUT1/2 (glutamate transporter), and actin. The signal densities were quantified. Each bar represents the mean $\pm \operatorname{SEM}(n=3$ for each group)

$A \beta$ production is increased by GABAergic depletion (Fig. 8). Intraneuronal accumulation of $A \beta$ has been shown to be an early event in both human patients and mouse models of $\mathrm{AD}[6,9,15,16,23,31]$. Once $A \beta$ oligomers accumulate, it triggers other neuropathologies of $\mathrm{AD}$, such as abnormal tau phosphorylation, synapse loss, glial activation, and eventual neuron loss, as previously demonstrated in $\mathrm{APP}_{\mathrm{OSK}}$ mice [26].

Regarding the recessive heredity of the Osaka mutation, some other possibilities are also considered. First, we cannot exclude the possibility that the recessive appearance of the Osaka mutation is due to its incomplete penetrance or variable expressivity. However, we have not observed such symptoms in our OSK-KI mice except for synapse loss in 24-month-old heterozygotes. Second, it may be that the presence of wild-type $A \beta$ interferes with the oligomerization of mutant $A \beta$, like the aforementioned recessive APP mutation A673V [5]. This is unlikely, however, because $\mathrm{APP}_{\mathrm{OSK}}$ mice that express both mutant and wild-type $A \beta$ at similar levels showed $A \beta$ oligomer accumulation [26]. Third, whether $A \beta$ oligomers accumulate in the brain may simply depend on the concentration of mutant $A \beta$. Homozygotes express a sufficient amount of mutant $A \beta$, whereas heterozygotes produce only a half amount that in homozygotes, not reaching pathogenic levels. We assume that even in homozygotes, the amount of mutant $A \beta$ is insufficient and GABAergic depletion is necessary for $A \beta$ oligomer accumulation, as described above.

GABAergic dysfunction may underlie the pathogenesis of AD, not only in the Osaka mutation but also in other familial and sporadic cases. For example, it has been reported that the levels of GABA are reduced in the posterior cingulated cortex of amnestic mild cognitive impairment independently of amyloid deposition [19] and in the parietal cortex of patients with AD [1]. Neuronal hyperactivity has also been observed in the presymptomatic stages of both sporadic and familial $\mathrm{AD}$ [21]. Furthermore, two major $\mathrm{A} \beta$-degrading enzymes, endothelin-converting enzyme- 2 and neprilysin, 
a

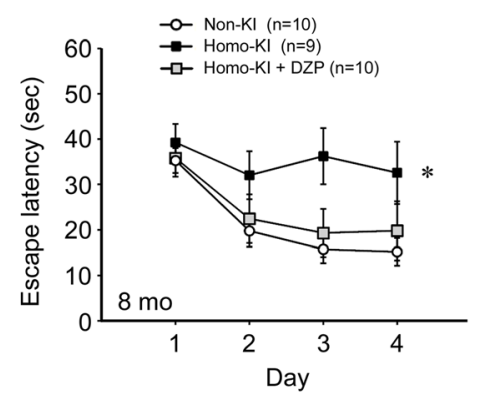

C
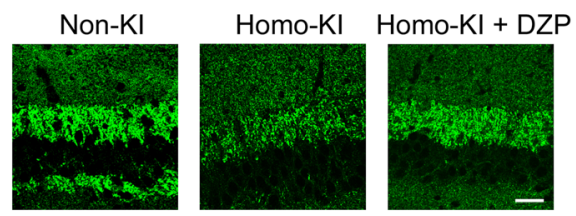

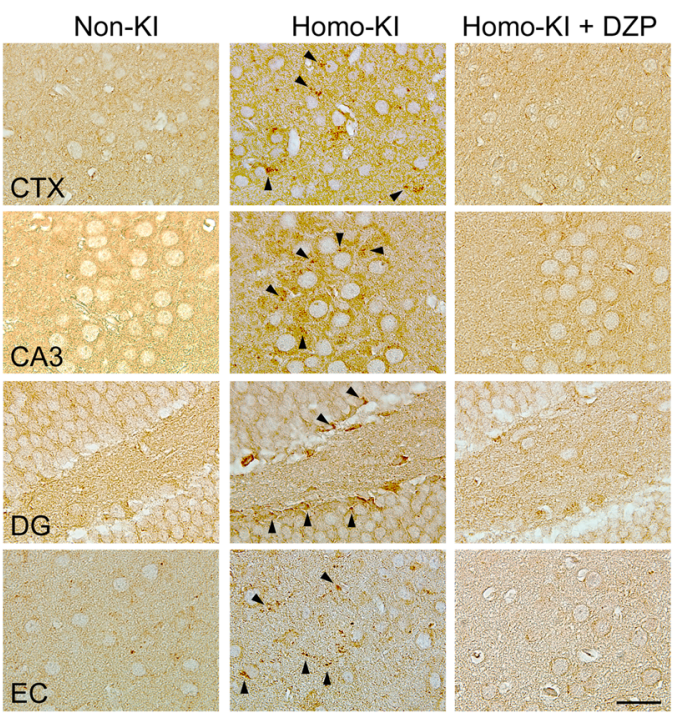

b

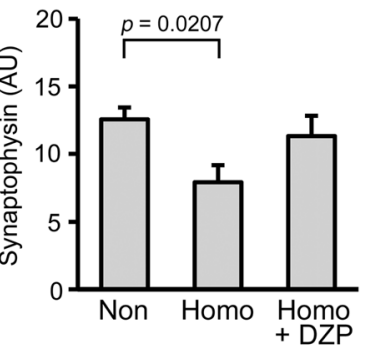

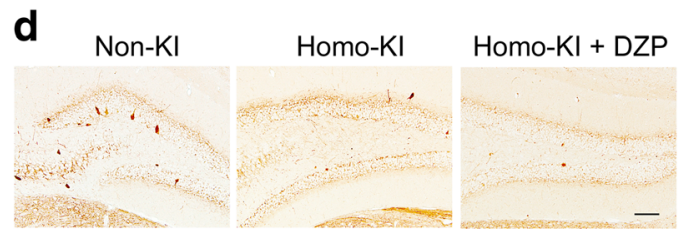

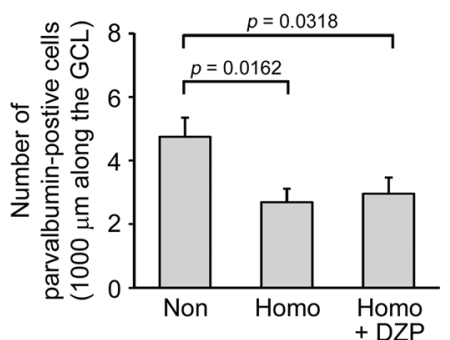

Fig. 7 Effects of diazepam treatment on memory and A $\beta$ pathology in OSK-KI mice. Diazepam (DZP) was orally administered to 6-month-old homo-KI mice at $2 \mu \mathrm{g} /$ day for 2 months. (a) Spatial reference memory was examined at 8 months using the Morris water maze. Each point represents the mean latency of five trials per day \pm SEM. ${ }^{*} p<0.05$ versus non-KI. (b) Brain sections were stained with $A \beta$ oligomer-specific $11 \mathrm{~A} 1$ antibody. Photographs were taken from the PPtA of the cerebral cortex (CTX), hippocampal CA3 region (CA3), dentate gyrus (DG), and entorhinal cortex (EC). Arrowheads indicate $A \beta$ accumulated within neurons. Scale bar $=30 \mu \mathrm{m}$. (c) Brain sections were stained with anti-synaptophysin antibody. Photographs were taken from the hippocampal CA3 region. Scale bar $=30 \mu \mathrm{m}$. Fluorescence intensities in a constant area were quantified. Each bar represents the mean \pm SEM ( $n=5$ for each group). AU, arbitrary unit. (d) Brain sections were stained with anti-parvalbumin antibody. Photographs were taken from the dentate gyrus. Scale bar $=30 \mu \mathrm{m}$. Parvalbumin-positive GABAergic neurons in a constant area in the granular cell layer (GCL) of the dentate gyrus were counted. Each bar represents the mean \pm SEM ( $n=5$ for each group)

were shown to be enriched in GABAergic interneurons in the hippocampus and neocortex [18], implying that GABAergic neuron loss results in lowered degradation and subsequent accumulation of $A \beta$. In this regard, it is noteworthy that previous use of benzodiazepine has been shown to be associated with lower cortical $A \beta$ levels in non-demented elderly control subjects [4]. These findings collectively implicate that pharmacological treatments to compensate GABAergic deficiency might have therapeutic potential in early stages of $\mathrm{AD}$ [12].

\section{Conclusions}

In summary, we elucidated here that the Osaka mutation has dual effects: it causes a loss-of-function of APP and gain-of-toxic-function of $A \beta$, though the latter seems to come out only after the former causes 


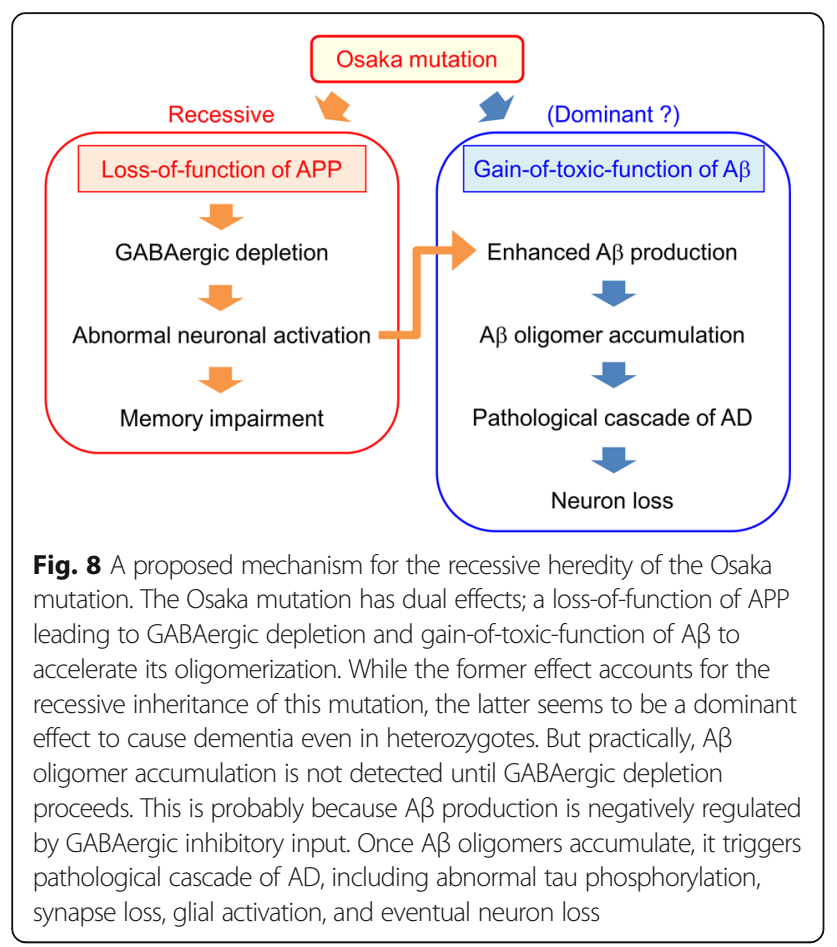

GABAergic depletion. To our knowledge, the present OSK-KI mice is the first mouse model to replicate the hereditary form of recessive familial $\mathrm{AD}$, though the phenotypes are not yet validated in human cases. Furthermore, the present study demonstrates for the first time that mutation-induced loss of APP function could be a cause of recessive hereditary dementia.

\section{Acknowledgements}

We thank Rie Teraoka, Naomi Sakama, Reina Fujita, Maiko Mori, and Taro Nishiyama for their technical assistance, and Peter Karagiannis for reading the manuscript.

\section{Funding}

This study was supported by the Grants-in-Aid for Scientific Research from the Ministry of Education, Culture, Sports, Science and Technology of Japan (no. 20023026, 21,390,271, 23,110,514, 25,290,018, 16 K15132); by the Grant-in-Aid for Scientific Research on Innovative Areas (Comprehensive Brain Science Network) from the Ministry of Education, Culture, Sports, Science and Technology of Japan; by the Grants-in-Aid for Comprehensive Research on Dementia from the Ministry of Health, Labour, and Welfare, Japan; and in part by the Alzheimer's Association (IIRG-09-132,098).

\section{Availability of data and materials}

The data generated and/or analyzed during the comprehensive behavioral test battery are available in the Mouse Phenotype Database [http:/ wwww.mousephenotype.org/J, while the other data are available from the corresponding author upon reasonable request. Inquiries about OSK-KI mice should be addressed to the corresponding author.

\section{Authors' contributions}

$\Pi$, HM, TMo, AT, and TMi contributed to the conception and design of the study. TU, TK, KY, KT, YF, SM, AS, MY, YY, KO, MS, HT, TMO, and TT performed experiments and analyzed data. $T$ drafted the manuscript and TU prepared main figures. All authors read and approved the final manuscript.

\section{Ethics approval}

All procedures performed in studies involving animals were in accordance with the ethical standards of the institution at which the studies were conducted.

\section{Consent for publication \\ Not applicable.}

\section{Competing interests}

Drs. Umeda, Yoshida, Morita, Mori, and Tomiyama have a Japanese patent (No. 2015-50,032) on the knockin mouse pending.

\section{Publisher's Note}

Springer Nature remains neutral with regard to jurisdictional claims in published maps and institutional affiliations.

\section{Author details}

'Department of Translational Neuroscience, Osaka City University Graduate School of Medicine, 1-4-3 Asahimachi, Abeno-ku, Osaka 545-8585, Japan.

${ }^{2}$ Core Research for Evolutional Science and Technology, Japan Science and Technology Agency, Kawaguchi, Japan. ${ }^{3}$ Department of Aging Neurobiology, Center for Development of Advanced Medicine for Dementia, National Center for Geriatrics and Gerontology, Obu, Japan. ${ }^{4}$ Department of Molecular Genetics, Osaka City University Graduate School of Medicine, Osaka, Japan. ${ }^{5}$ Section of Behavior Patterns, Center for Genetic Analysis of Behavior, National Institute for Physiological Sciences, Okazaki, Japan. ${ }^{6}$ Biosignal Research Center, Kobe University, Kobe, Japan. 'Department of Clinical Neuroscience, Osaka City University Medical School, Osaka, Japan. ${ }^{8}$ Present address: Life Science Research Center, University of Toyama, Toyama, Japan.

Received: 4 July 2017 Accepted: 21 July 2017

Published online: 31 July 2017

\section{References}

1. Bai X, Edden RA, Gao F, Wang G, Wu L, Zhao B, Wang M, Chan Q, Chen W, Barker PB (2015) Decreased $\gamma$-aminobutyric acid levels in the parietal region of patients with Alzheimer's disease. J Magn Reson Imaging 41:1326-1331

2. Benilova I, Karran E, De Strooper B (2012) The toxic A $\beta$ oligomer and Alzheimer's disease: an emperor in need of clothes. Nat Neurosci 15:349-357

3. Cacace R, Sleegers K, Van Broeckhoven C (2016) Molecular genetics of earlyonset Alzheimer's disease revisited. Alzheimers Dement 12:733-748

4. Chung JK, Nakajima S, Shinagawa S, Plitman E, Chakravarty MM, Iwata Y, Caravaggio F, Pollock BG, Gerretsen P, Graff-Guerrero A, Initiative A's DN (2016) Benzodiazepine use attenuates cortical $\beta$-Amyloid and is not associated with progressive cognitive decline in nondemented elderly adults: a pilot study using $\mathrm{F}_{18}$-Florbetapir positron emission tomography. Am J Geriatr Psychiatry 24:1028-1039

5. Di Fede G, Catania M, Morbin M, Rossi G, Suardi S, Mazzoleni G, Merlin M, Giovagnoli AR, Prioni S, Erbetta A, Falcone C, Gobbi M, Colombo L, Bastone A, Beeg M, Manzoni C, Francescucci B, Spagnoli A, Cantù L, Del Favero E, Levy E, Salmona M, Tagliavini F (2009) A recessive mutation in the APP gene with dominant-negative effect on amyloidogenesis. Science 323:1473-1477

6. Gouras GK, Tsai J, Naslund J, Vincent B, Edgar M, Checler F, Greenfield JP, Haroutunian V, Buxbaum JD, Xu H, Greengard P, Relkin NR (2000) Intraneuronal Abeta42 accumulation in human brain. Am J Pathol 156:15-20

7. Jonsson T, Atwal JK, Steinberg S, Snaedal J, Jonsson PV, Bjornsson S, Stefansson H, Sulem P, Gudbjartsson D, Maloney J, Hoyte K, Gustafson A, Liu Y, Lu Y, Bhangale T, Graham RR, Huttenlocher J, Bjornsdottir G, Andreassen OA, Jönsson EG, Palotie A, Behrens TW, Magnusson OT, Kong A, Thorsteinsdottir U, Watts RJ, Stefansson K (2012) A mutation in APP protects against Alzheimer's disease and age-related cognitive decline. Nature 488:96-99

8. Kamenetz F, Tomita T, Hsieh H, Seabrook G, Borchelt D, Iwatsubo T, Sisodia S, Malinow R APP processing and synaptic function. Neuron 37:925-37

9. Knobloch M, Konietzko U, Krebs DC, Nitsch RM (2007) Intracellular Abeta and cognitive deficits precede beta-amyloid deposition in transgenic arcAbeta mice. Neurobiol Aging 28:1297-1306

10. Koshimizu H, Takao K, Matozaki T, Ohnishi H, Miyakawa T (2014) Comprehensive behavioral analysis of cluster of differentiation 47 knockout mice. Plos One 9:e89584

11. Kutoku Y, Ohsawa Y, Kuwano R, Ikeuchi T, Inoue H, Ataka S, Shimada H, Mori H, Sunada Y (2015) A second pedigree with amyloid-less familial 
Alzheimer's disease harboring an identical mutation in the amyloid precursor protein gene (E693delta). Intern Med 54:205-208

12. Nava-Mesa MO, Jiménez-Díaz L, Yajeya J, Navarro-Lopez JD (2014) GABAergic neurotransmission and new strategies of neuromodulation to compensate synaptic dysfunction in early stages of Alzheimer's disease. Front Cell Neurosci 8:167

13. Nishitsuji K, Tomiyama T, Ishibashi K, Ito K, Teraoka R, Lambert MP, Klein WL, Mori H (2009) The E693Delta mutation in amyloid precursor protein increases intracellular accumulation of amyloid beta oligomers and causes endoplasmic reticulum stress-induced apoptosis in cultured cells. Am J Pathol 174:957-969

14. O'Brien RJ, Wong PC (2011) Amyloid precursor protein processing and Alzheimer's disease. Annu Rev Neurosci 34:185-204

15. Oddo S, Caccamo A, Shepherd JD, Murphy MP, Golde TE, Kayed R, Metherate R, Mattson MP, Akbari Y, LaFerla FM (2003) Triple-transgenic model of Alzheimer's disease with plaques and tangles: intracellular Abeta and synaptic dysfunction. Neuron 39:409-421

16. Oddo S, Caccamo A, Smith IF, Green KN, LaFerla FM (2006) A dynamic relationship between intracellular and extracellular pools of Abeta. Am J Pathol 168:184-194

17. Ovsepian SV, O'Leary VB (2016) Neuronal activity and amyloid plaque pathology: an update. J Alzheimers Dis 49:13-19

18. Pacheco-Quinto J, Eckman CB, Eckman EA (2016) Major amyloid- $\beta$ degrading enzymes, endothelin-converting enzyme-2 and neprilysin, are expressed by distinct populations of GABAergic interneurons in hippocampus and neocortex. Neurobiol Aging 48:83-92

19. Riese F, Gietl A, Zölch N, Henning A, O'Gorman R, Kälin AM, Leh SE, Buck A, Warnock G, Edden RA, Luechinger R, Hock C, Kollias S, Michels $L$ (2015) Posterior cingulate $\gamma$-aminobutyric acid and glutamate/ glutamine are reduced in amnestic mild cognitive impairment and are unrelated to amyloid deposition and apolipoprotein E genotype. Neurobiol Aging 36:53-59

20. Shimada H, Ataka S, Tomiyama T, Takechi H, Mori H, Miki T (2011) Clinical course of patients with familial early-onset Alzheimer's disease potentially lacking senile plaques bearing the E693 $\Delta$ mutation in amyloid precursor protein. Dement Geriatr Cogn Disord 32:45-54

21. Stargardt A, Swaab DF, Bossers K (2015) Storm before the quiet: neuronal hyperactivity and $A B$ in the presymptomatic stages of Alzheimer's disease. Neurobiol Aging 36:1-11

22. Strachan T, Read A (2010) Human Molecular Genetics, 4th edn. Garland Science, New York

23. Takahashi RH, Milner TA, Li F, Nam EE, Edgar MA, Yamaguchi H, Beal MF, Xu H, Greengard P, Gouras GK (2002) Intraneuronal Alzheimer abeta42 accumulates in multivesicular bodies and is associated with synaptic pathology. Am J Pathol 161:1869-1879

24. Thuy le TT, Morita T, Yoshida K, Wakasa K, lizuka M, Ogawa T, Mori M, Sekiya Y, Momen S, Motoyama H, Ikeda K, Yoshizato K, Kawada N (2011) Promotion of liver and lung tumorigenesis in DEN-treated cytoglobin-deficient mice. Am J Pathol 179:1050-1060

25. Tomiyama T, Nagata T, Shimada H, Teraoka R, Fukushima A, Kanemitsu $H$, Takuma H, Kuwano R, Imagawa M, Ataka S, Wada Y, Yoshioka E, Nishizaki T, Watanabe $Y$, Mori H (2008) A new amyloid beta variant favoring oligomerization in Alzheimer's-type dementia. Ann Neurol 63:377-387

26. Tomiyama T, Matsuyama S, Iso H, Umeda T, Takuma H, Ohnishi $\mathrm{K}$, Ishibashi K, Teraoka R, Sakama N, Yamashita T, Nishitsuji K, Ito K, Shimada H, Lambert MP, Klein WL, Mori H (2010) A mouse model of amyloid beta oligomers: their contribution to synaptic alteration, abnormal tau phosphorylation, glial activation, and neuronal loss in vivo. J Neurosci 30:4845-4856

27. Tu S, Okamoto S, Lipton SA, Xu H (2014) Oligomeric Aß-induced synaptic dysfunction in Alzheimer's disease. Mol Neurodegener 9:48

28. Umeda T, Ono K, Sakai A, Yamashita M, Mizuguchi M, Klein WL, Yamada M Mori H, Tomiyama T (2016) Rifampicin is a candidate preventive medicine against amyloid-beta and tau oligomers. Brain 139:1568-1586

29. Viola KL, Klein WL (2015) Amyloid $\beta$ oligomers in Alzheimer's disease pathogenesis, treatment, and diagnosis. Acta Neuropathol 129:183-206

30. Wang B, Wang Z, Sun L, Yang L, Li H, Cole AL, Rodriguez-Rivera J, Lu $H C$, Zheng H (2014) The amyloid precursor protein controls adult hippocampal neurogenesis through GABAergic interneurons. J Neurosci 34:13314-13325
31. Wirths O, Multhaup G, Czech C, Blanchard V, Moussaoui S, Tremp G, Pradier L, Beyreuther K, Bayer TA (2001) Intraneuronal Abeta accumulation precedes plaque formation in beta-amyloid precursor protein and presenilin-1 double-transgenic mice. Neurosci Lett 306:116-120

32. Yoshiike Y, Kimura T, Yamashita S, Furudate H, Mizoroki T, Murayama M, Takashima A (2008) GABA(a) receptor-mediated acceleration of agingassociated memory decline in APP/PS1 mice and its pharmacological treatment by picrotoxin. Plos One 3:e3029

\section{Submit your next manuscript to BioMed Central and we will help you at every step:}

- We accept pre-submission inquiries

- Our selector tool helps you to find the most relevant journal

- We provide round the clock customer support

- Convenient online submission

- Thorough peer review

- Inclusion in PubMed and all major indexing services

- Maximum visibility for your research

Submit your manuscript at www.biomedcentral.com/submit

) Biomed Central 